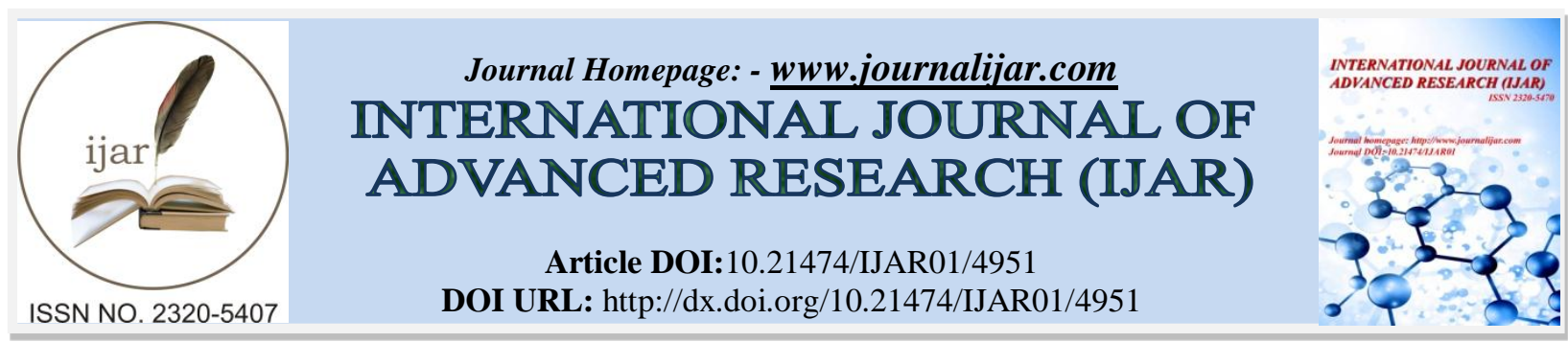

RESEARCH ARTICLE

\title{
OSTEOID OSTEOMA OF THE FIRST METACARPAL BONE: A CASE REPORT.
}

\section{O. Zaddoug, A. Elghazoui, MR Bensaleh, A Bennabouha, MR. Ouzaa, A. Bennis, M. Benchekroun, A. Zine, M. Tanan and A. Jaafar. \\ Department of Traumatology Orthopedics I. Military Hospital Mohamed V of Rabat. -faculty of medicine and pharmacy of flap. -university mohamed 5 from rabat- Morocco.}

\section{Manuscript Info}

..........................

Manuscript History

Received: 25 May 2017

Final Accepted: 27 June 2017

Published: July 2017

\section{Abstract}

Osteoid osteoma is a benign bone tumor. A few cases of metacarpal osteoid osteoma have been reported, but the phalanges are the most frequent sites in the hand, followed by the carpal bones. We report a case of an osteoid osteoma of the right first metacarpal bone in a 32year-old woman. The clinical and radiographic findings along with the pathology results are presented. At the 1 year follow-up there was no evidence of recurrence. Finally, Osteoid osteoma of the metacarpal bones should be considered in the diagnosis of chronic pain in the hand of a young patient, presenting with or without a history of previous injury

Copy Right, IJAR, 2017,. All rights reserved.

\section{Introduction:-}

Osteoid osteoma represents $10 \%$ of all benign bone tumors with a localization in the wrist and the hand in $6 \%$ to $13 \%$ of reported cases only [1,2]. The phalanges are the most frequent sites [3], followed by the carpal bone and finally the metacarpals which are the least common sites [4]. We report a cas of osteoid osteoma of the first metacarpal in a young patient and describe the clinical presentation, radiological findings and successful outcome after surgical excision of the lesion

\section{Case Report:-}

A 32 year-old woman, whitout any antecedent of injury, was referred to our hospital last year with history of pain in her first right finger. The pain increased at night and was reduced by non-steroidal anti-inflammatory agents. The physical examination was normal and the radiographs showed an extension of the metaphysis of the right first metacarpal bone (Figure 1a).

Corresponding Author:-O. Zaddoug. 


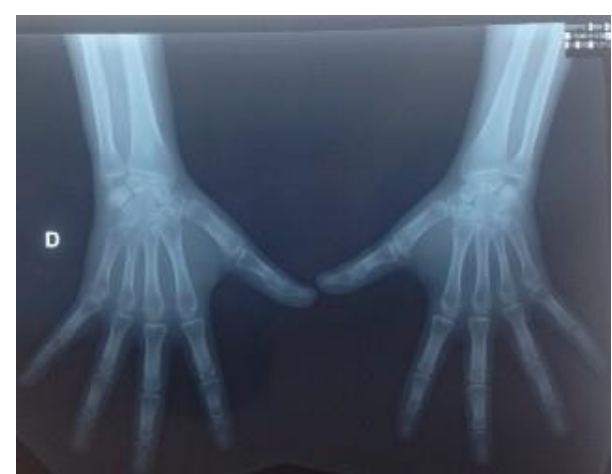

Figure 1a:- Radiograph of two hands an extension of the metaphysis of the right first metacarpal bone

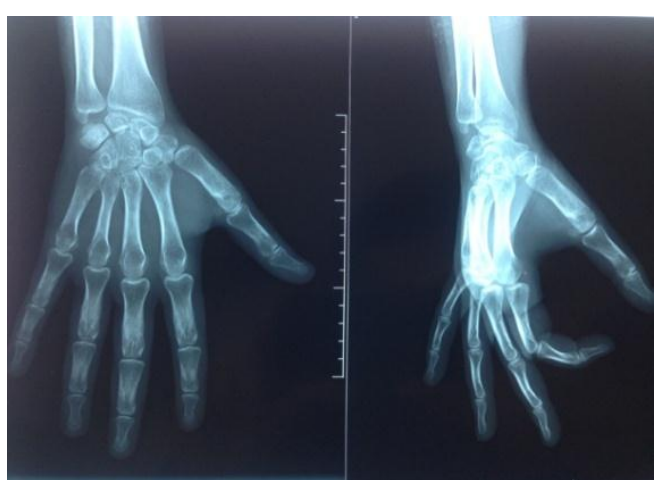

Figure 1b:- Radiograph of the right hand showing the absence of radiological reccurence after one year follow-up

Computed tomography revealed an oval radiolucent zone marked sclerosis around the lesion (nidus) pointing to the diagnosis of an osteoid osteoma of the first metacarpal bone (Figure 2).

A curettage of the nidus was performed (Figure 3) and the hand was immobilized with a splint

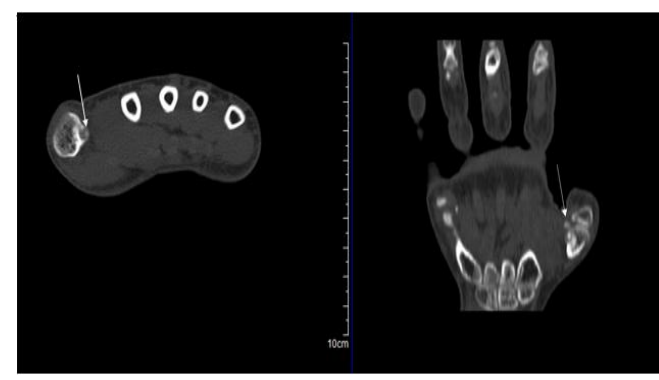

Figure 2:- Computed tomography showing the radiolucent zone and the marked sclerosis around the lesion.

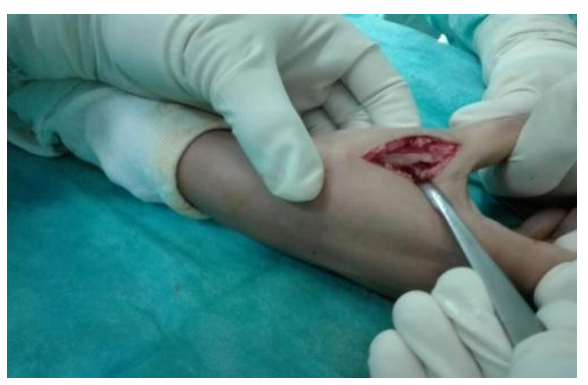

Figure 3:- Curettage of the osteoid osteoma of the first metacarpal bone

Histological examination confirmed the diagnosis of osteoid osteoma (Figure 4). The patient was pain-free immedialely after excision without any non-steroidal anti-inflammatory agents. After 1 year, the patient was relieved of pain and follow up radiographs shows there was no evidence of recurrence (Figures $1 \mathrm{~b}$ and 5).

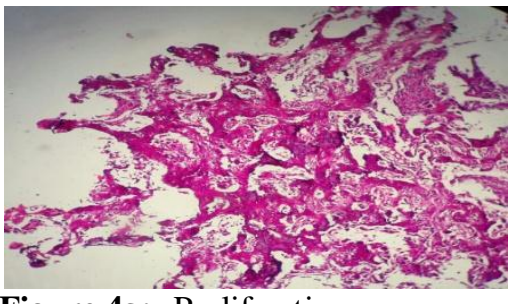

Figure 4a:- Proliferation established by interlooked bone trabeculae

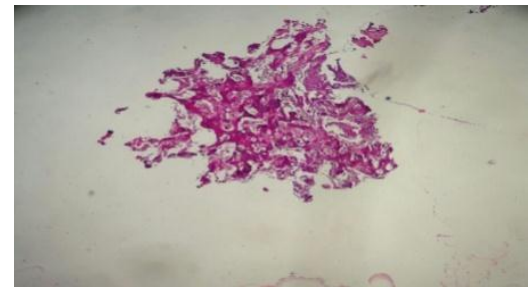

Figure 4b:- Trabeculae of bone has different sizes surrounded by a heavy connective tissue

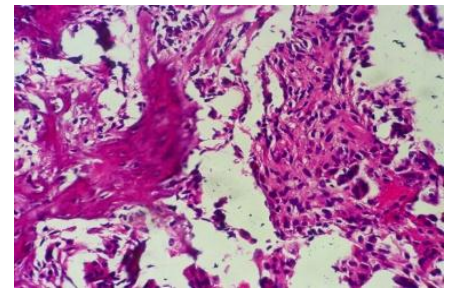

Figure 4c:- Trabeculae of bone are surrounded by a continious border of osteoblasts and few osteoclasts 

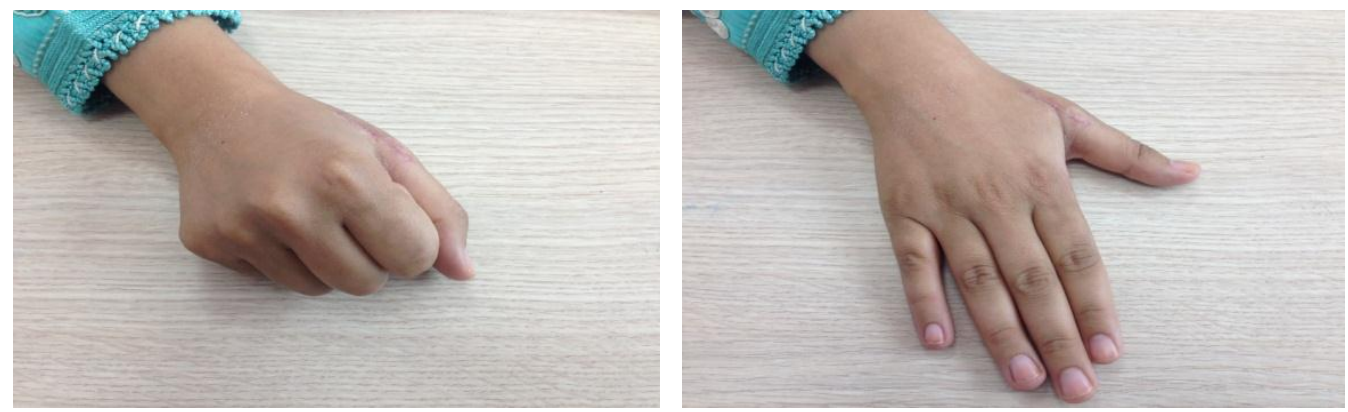

Figure 5:- No functional after effects after one-year follow-up

\section{Discussion:-}

Osteoid osteoma represents $10 \%$ of all benign bone tumors [1,2]. It usually affects children and young adults with more than $50 \%$ of localizations in the tibia and femur, $8 \%$ in the hand with predilection for phalanges [3] followed by the carpal bones and the metacarpals which are exceptionally affected [4].

Clinical presentation of osetoid osteoma is dominated by the pain which increased at night and reduced by salicylates in $73 \%$ of reported cases. Antecedent of injury was reported in some studies without correlation between injury and the onset of osteoid osteoma. Computed tomographie confirmes diagnosis by showing an oval or round infracentimetric nidus surrounded by radiolucent zone [5].

Surgical excision of the nidus still the treatment of choice [3] comparing to minimally invasive techniques [5] like radiofrequency ablation, thermal destruction with laser photocoagulation, and percutaneous trephine or drill resection with or without ethanol injection [6-9] which expose to more risques of recurrence.

Recurrences occurs in the first 7 months after surgical excision and it is, almost, due to partial resection of the nidus [10].

The diagnosis of osteoid osteoma of the hand is difficult due to his atypical clinical and radiological presentation, It should be considered in the diagnosis of chronic pain in the hand of a young patient.

Finally, the curettage of the nidus is the key of diagnosis and treatment.

\section{References:-}

1. Bulbul M, Ayanoglu S, Ozturk K, Gurkan V, Gurbuz H, Bilgiç B (2010) Osteoid osteoma of a mecacarpal bone: case report. Trakya Univ Tip Fak Derg 27(2):209-211

2. Marcuzzi A, Leti Acciaro A, Landi A (2002) Osteoid osteoma of the hand and wrist. J Hand Surg (Br Eur) 27 $\mathrm{B}(5): 440-443$

3. Muren C, Hoglund M, Engkvist O, Juhlin L: Osteoid osteomas of the hand. Report of three cases and review of the literature. Acta Radiol 1991, 32:62-66.

4. Chronopoulos E, Xypnitos FN, Nikolaou VS, Efstathopoulos N, Korres D (2008) Osteoid osteoma of a metacarpal bone: a case report and review of the literature. J Med Case Rep 2:285

5. Chai JW, Hong SH, Choi J-Y, Koh YH, Lee JW, Choi J-A et al. Radiologic diagnosis of osteoid osteoma: from simple to challenging findings. Radiographics. 2010; 30 (3):737- 49.

6. Becce F, Theumann N, Rochette A, Larousserie F, Campagna R, Cherix S et al. Osteoid osteoma and osteoid osteomamimicking lesions: biopsy findings, distinctive MDCT features and treatment by radiofrequency ablation. Eur Radiol. 2010; 20(10):2439-46.

7. Towbin R, Kaye R, Meza MP, Pollock AN, Yaw K, Moreland M (1995) Osteoid osteoma: percutaneous excision using a CT guided coaxial technique. AJR AMJ Roentgenol 164:945-949

8. Adam G, Neverburg J, Vorwerk D, Forst J, Gunther RW (1997) Percutaneous treatment of osteoid osteomas: combination of drill biopsy and subsequent ethanol injection. Semin Musculoskelet Radiol 1:281-284

9. Vanderschueren GM, Taminiau AH, Obermann WR (2002) Bloem JL: osteoid osteoma : clinical results with thermocoagulation. Radiology 224:82-86

10. Norman A (1978) Persistence or recurrence of pain: a sign of surgical failure in osteoid osteoma. Clin Orthop Relat Res 130:263-266. 